\title{
Kinetics and mechanisms of cadmium carbonate heteroepitaxial growth at the calcite $(10 \overline{1} 4)$ surface
}

\author{
Man $\mathrm{Xu}^{\mathrm{a}, *}$, Libor Kovarik ${ }^{\mathrm{b}}$, Bruce W. Arey ${ }^{\mathrm{b}}$, Andrew R. Felmy ${ }^{\mathrm{a}}$, \\ Kevin M. Rosso ${ }^{a}$, Sebastien Kerisit ${ }^{\text {a,* }}$ \\ a Fundamental and Computational Sciences Directorate, Physical Sciences Division, Pacific Northwest National Laboratory, Richland, \\ WA 99352, USA \\ ${ }^{\mathrm{b}}$ Environmental Molecular Sciences Laboratory, Scientific Resources Division, Pacific Northwest National Laboratory, Richland, WA \\ 99352, USA
}

Received 10 June 2013; accepted in revised form 26 November 2013; available online 6 December 2013

\begin{abstract}
Elucidating the kinetics and mechanisms of heteroepitaxial nucleation and growth at mineral-water interfaces is essential to understanding surface reactivity in geochemical systems. In the present work, the formation of heteroepitaxial cadmium carbonate coatings at calcite-water interfaces was investigated by exposing calcite (1014) surfaces to Cd-bearing aqueous solutions. In situ atomic force microscopy (AFM) was employed as the primary technique. The AFM results indicate that the heteroepitaxial growth of cadmium carbonate proceeds via three different mechanisms depending on the initial supersaturation of the aqueous solution: advancement of existing steps, nucleation and growth of three-dimensional (3D) islands, and nucleation and spread of two-dimensional (2D) nuclei. The 3D islands and 2D nuclei exhibit different morphologies and growth kinetics. The effects of supersaturation on heteroepitaxial growth mechanisms can be interpreted in terms of the free energy barrier for nucleation. At low initial supersaturation, where 3D nucleation dominates, it is hypothesized, from the growth rate and morphology of the 3D islands observed with AFM, that the crystallization of the overgrowth follows a non-classical pathway involving the formation of a surface precursor that is not fully crystalline, whereas high supersaturation favors the formation of crystalline 2D nuclei whose morphology is based on the atomic structure of the calcite substrate. Cross-sectional transmission electron microscopy (TEM) images reveal that the atomic structure of the interface between the cadmium carbonate coating and calcite shows perfect, dislocation-free epitaxy.
\end{abstract}

(c) 2013 Elsevier Ltd. All rights reserved.

\section{INTRODUCTION}

Mineral surfaces are active substrates for heterogeneous nucleation and can support the growth of heteroepitaxial coating phases from aqueous solution if the atomic arrangement of the substrate closely matches that of the nucleating phase (van der Merwe, 1949; Schulz, 1951; Lisgarten, 1954). Coating phases alter or ultimately obscure

\footnotetext{
* Corresponding authors.

E-mail addresses: man.xu@pnnl.gov (M. Xu), sebastien.kerisit@pnnl.gov (S. Kerisit).
}

the reactive properties of mineral surfaces (Cubillas et al., 2005). For example, Martin and co-workers (Jun et al., 2005; Na and Martin, 2008, 2009) showed, using scanning probe microscopy, that manganese oxide heteroepitaxial nanostructures grown on manganese carbonate surfaces exhibited vastly different interfacial forces than their substrate, indicative of different surface charges. Therefore, mineral heteroepitaxial coatings of even nanometer scale can significantly affect some properties of the mineral-water interface. In addition, the effect of heteroepitaxial coatings on mineral surface reactivity can lead to non-equilibrium conditions. For example, due to the low solubility of some 
metal carbonates such as otavite $\left(\mathrm{CdCO}_{3}\right)$ and rhodochrosite $\left(\mathrm{MnCO}_{3}\right)$ with respect to calcite $\left(\mathrm{CaCO}_{3}\right)$, even low concentrations of metal ions in the presence of a calcite surface are sufficient to cause the formation of a heteroepitaxial mineral coating (Pérez-Garrido et al., 2007, 2009). Such coatings can extend sufficiently to effectively armor the original calcite surface, limiting access to and hindering further reaction of the initial substrate, which prevents the aqueous solution from reaching equilibrium with respect to the $\mathrm{CaCO}_{3}$ phase. Collectively, observations such as these provide important clues for identifying properties of heteroepitaxial coatings at mineral-water interfaces that need to be better understood to enhance our ability to predict non-equilibrium conditions.

In this work, we consider the growth of cadmium carbonate on the calcite $(10 \overline{1} 4)$ surface as a geochemically-relevant model system for probing the rates and mechanisms of heteroepitaxial growth at mineral-water interfaces. The experiments are performed in the heterogeneous nucleation regime whereby the solution is undersaturated with respect to the calcite substrate but supersaturated with respect to otavite. Of all the anhydrous metal carbonates that adopt the calcite structure, otavite offers the smallest misfit with respect to the calcite lattice $(-4 \%$ based on the calcite and otavite $(10 \overline{1} 4)$ surface areas). Combined with the much lower solubility of otavite $\left(\log K_{\mathrm{sp}}=-12.24\right.$ (Rai et al., 1991)) compared to that of calcite $\left(\log K_{\mathrm{sp}}=-8.48\right.$ (Plummer et al., 1978)), this makes the heteroepitaxial growth of otavite on calcite amenable to measuring growth rates on the time scale of laboratory experiments.

Early work on the reaction of cadmium with calcite powders showed a strong affinity of cadmium for the calcite surface and evidence of otavite formation, based on cadmium aqueous concentrations that were controlled by otavite solubility (McBride, 1980; Papadopoulos and Rowell, 1988). The later use of surface sensitive techniques provided microscopic information on the composition and structure of precipitates on calcite single crystals. A combination of X-ray photoelectron spectroscopy (XPS) and low-energy electron diffraction (LEED) measurements by Stipp et al. (1992) indicated that almost pure $\mathrm{CdCO}_{3}$ had grown on the calcite substrate, as evidenced by high $\mathrm{Cd} / \mathrm{Ca}$ ratios, and that the coating was crystalline with lattice parameters consistent with those of calcite and otavite. Chiarello and co-workers (Chiarello and Sturchio, 1994; Chiarello et al., 1997) showed from synchrotron X-ray reflectivity (XRR) and X-ray diffraction (XRD) measurements that a calcite-otavite solid solution could grow epitaxially on the $(10 \overline{1} 4)$ calcite surface with thicknesses of up to several tens of nanometers. These seminal studies provided direct evidence for heteroepitaxial growth of otavite on calcite but could only indirectly determine growth mechanisms. More recently, atomic force microscopy (AFM) was used to follow, in situ, the reaction of Cd-bearing solutions with single crystals of calcite (Hay et al., 2003; Pérez-Garrido et al., 2007; Cubillas and Higgins, 2009). Cubillas and Higgins (2009) focused on growth experiments in flow-through conditions with a high initial $\mathrm{Cd}$ concentration $\left(\left[\mathrm{Cd}^{2+}\right]_{0}=0.1 \mathrm{mM}\right)$ and reported monolayer growth either through advancement of existing steps or two-dimensional nucleation. Pérez-Garrido et al.
(2007) explored lower initial $\mathrm{Cd}$ concentrations $\left(0.005 \mathrm{mM} \leqslant\left[\mathrm{Cd}^{2+}\right]_{0} \leqslant 0.050 \mathrm{mM}\right)$ in static conditions and observed the formation of three-dimensional islands that were elongated along the $[42 \overline{1}]$ direction and had fixed heights of approximately $2.75 \mathrm{~nm}$. Although growth rates were reported for some of the experiments in these two studies, a systematic investigation of the dependence of growth rates on the initial level of supersaturation is still lacking.

In this study, we build upon previous work by systematically measuring the morphology and growth rates of surface features over a wide range of initial concentrations $\left(0.001 \mathrm{mM} \leqslant\left[\mathrm{Cd}^{2+}\right]_{0} \leqslant 0.100 \mathrm{mM}\right)$ using AFM to quantify the factors that control the kinetics of heteroepitaxial growth, and to determine the dominant growth mechanisms as a function of saturation state. Such measurements will serve to help establish a microscopic model of heteroepitaxy in aqueous environments. Additionally, this work will determine whether the growth mechanisms observed in different studies under different growth conditions can be unified under a single approach. Finally, we aim to gain a unique perspective on the atomic-level structure of the interface between the calcite substrate and the coating phase through the use of cross-sectional transmission electron microscopy (TEM).

\section{EXPERIMENTAL}

\subsection{In situ AFM experiments}

Optically-clear calcite crystals originated in Brazil were used to prepare specimens of approximately $10 \mathrm{~mm} \times$ $12 \mathrm{~mm} \times 1.5 \mathrm{~mm}$ in size by cleaving with a razor blade along the $(10 \overline{1} 4)$ cleavage minutes before performing the experiments. Aqueous solutions were prepared from high-purity $\mathrm{CdCl}_{2}(99.999 \%)$ dissolved in deionized water (resistivity $\sim 18 \mathrm{M} \Omega$ ). All the growth experiments were carried out in the AFM fluid cell. The fluid cell was a custom-built KelF cell with a diameter of $2.7 \mathrm{~cm}$ and a volume of approximately $2.5 \mathrm{~mL}$. The calcite specimens were fixed in the fluid cell, which remained open to air throughout the experiments. In situ AFM (Bruker, Dimension Icon) experiments were carried out in static conditions by first contacting the calcite surfaces with $2.3 \mathrm{~mL}$ deionized water for exactly $30 \mathrm{~min}$, followed by the introduction of a small volume $(50-100 \mu \mathrm{L})$ of concentrated $\mathrm{CdCl}_{2}$ solution to obtain an initial $\mathrm{Cd}^{2+}$ concentration, $\left[\mathrm{Cd}^{2+}\right]_{0}$, of $0.001-0.1 \mathrm{mM}$. AFM images were then taken every few minutes for $2-6 \mathrm{~h}$. Control experiments without the addition of $\mathrm{Cd}^{2+}$ were also completed for comparison. In additional experiments aimed to evaluate the composition of the overgrowing phase, both cadmium and calcium were introduced in the aqueous solutions to yield initial concentrations of $\left[\mathrm{Cd}^{2+}\right]_{0}=0.050 \mathrm{mM}$ and $0.050 \mathrm{mM} \leqslant\left[\mathrm{Ca}^{2+}\right]_{0} \leqslant 0.180 \mathrm{mM}$. Based on inductively coupled plasma optical emission spectrometry (ICP-OES) (Perkin-Elmer, Optima 2100DV) and pH measurements, PHREEQC (U.S. Geological Survey computer program) calculations showed that, at the point of $\mathrm{CdCl}_{2}$ addition,

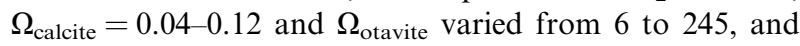
that, for the mixed $\mathrm{Cd} / \mathrm{Ca}$ solutions, $\Omega_{\text {calcite }}$ and $\Omega_{\text {otavite }}$ varied from 0.09 to 0.17 and from 162 to 174 , respectively, 
Table 1

Ion activities and saturation states of the initial experimental solutions.

\begin{tabular}{lllllll}
\hline$\left[\mathrm{Cd}^{2+}\right]_{0}(\mathrm{mM})$ & Added $\left[\mathrm{Ca}^{2+}\right](\mathrm{mM})$ & $\Omega_{\text {otavite }}$ & $\Omega_{\text {calcite }}$ & $a_{\mathrm{Cd}^{2+}}$ & $a_{\mathrm{Ca}^{2+}}$ \\
\hline 0.000 & - & - & 0.12 & - & $a_{\mathrm{CO}_{3}^{2-}}$ \\
0.001 & - & 6 & 0.11 & $7.2 \times 10^{-7}$ & $7.4 \times 10^{-5}$ & $5.2 \times 10^{-6}$ \\
0.002 & - & 13 & 0.11 & $1.4 \times 10^{-6}$ & $7.4 \times 10^{-5}$ & $5.0 \times 10^{-6}$ \\
0.005 & - & 30 & 0.11 & $3.6 \times 10^{-6}$ & $7.4 \times 10^{-5}$ & $4.8 \times 10^{-6}$ \\
0.010 & - & 56 & 0.10 & $7.3 \times 10^{-6}$ & $7.4 \times 10^{-5}$ & $4.4 \times 10^{-6}$ \\
0.018 & - & 91 & 0.09 & $1.3 \times 10^{-5}$ & $7.4 \times 10^{-5}$ & $3.9 \times 10^{-6}$ \\
0.025 & - & 117 & 0.08 & $1.9 \times 10^{-5}$ & $7.4 \times 10^{-5}$ & $3.5 \times 10^{-6}$ \\
0.038 & - & 155 & 0.07 & $2.9 \times 10^{-5}$ & $7.3 \times 10^{-5}$ & $3.0 \times 10^{-6}$ \\
0.050 & - & 182 & 0.06 & $3.9 \times 10^{-5}$ & $7.3 \times 10^{-5}$ & $2.6 \times 10^{-6}$ \\
0.070 & - & 214 & 0.05 & $5.6 \times 10^{-5}$ & $7.3 \times 10^{-5}$ & $2.2 \times 10^{-6}$ \\
0.100 & - & 245 & 0.04 & $8.0 \times 10^{-5}$ & $7.2 \times 10^{-5}$ & $1.8 \times 10^{-6}$ \\
0.050 & 0.050 & 174 & 0.09 & $3.8 \times 10^{-5}$ & $1.2 \times 10^{-4}$ & $2.6 \times 10^{-6}$ \\
0.050 & 0.100 & 170 & 0.12 & $3.8 \times 10^{-5}$ & $1.6 \times 10^{-4}$ & $2.6 \times 10^{-6}$ \\
0.050 & 0.150 & 162 & 0.15 & $3.7 \times 10^{-5}$ & $2.0 \times 10^{-4}$ & $2.5 \times 10^{-6}$ \\
0.050 & 0.180 & 162 & 0.17 & $3.7 \times 10^{-5}$ & $2.3 \times 10^{-4}$ & $2.5 \times 10^{-6}$ \\
\hline
\end{tabular}

as summarized in Table 1. $\Omega$, the saturation state of the solution, is defined as:

$\Omega=\frac{Q}{K_{\mathrm{sp}}}=\frac{a_{\mathrm{M}^{2+}} a_{\mathrm{CO}_{3}^{2-}}}{K_{\mathrm{sp}}}$

where $\mathrm{M}^{2+}$ refers to $\mathrm{Cd}^{2+}$ or $\mathrm{Ca}^{2+}, a_{\mathrm{M}}^{2+}$ and $a_{\mathrm{CO}_{3}{ }^{2-}}$ are ion activities, $\mathrm{Q}$ is the ionic activity product, and $\mathrm{K}_{\mathrm{sp}}$ is the solubility product for otavite or calcite. The equilibrium constants derived by Rai et al. (1991) were used for modeling $\mathrm{Cd}^{2+}-\mathrm{CO}_{3}^{2-}$ ion pairing.

AFM height and deflection images were collected in contact mode using Au coated silicon nitride probes (Bruker, $\mathrm{NP}-10$, nominal force constant of $0.12 \mathrm{~N} \mathrm{~m}^{-1}$ ). The externally applied load was $\sim 15 \mathrm{nN}$ to minimize the perturbation of the cantilever tip on mineral surface reactions. The scanning frequency was $0.5-0.8 \mathrm{~Hz}$, with 256 sampling points per scan line and scanning areas ranging from 9 to $100 \mu^{2}$. The growth rates of nuclei as well as etch pits expanding (or closing) rates were measured from timesequential AFM images scanned in the same direction. Images were flattened with order 2 . The consistency of the measured growth rates was verified using nuclei and etch pits from up to three replicate experiments for each value of $\left[\mathrm{Cd}^{2+}\right]_{0}$. All experiments were conducted at $\sim 22^{\circ} \mathrm{C}$.

\subsection{Ex situ TEM experiments}

TEM analysis was carried out to probe the atomic-level structure of the interface between calcite and otavite. A fluid cell with the same characteristics as that described in Section 2.1, but with added inlet and outlet, was used to grow otavite in flow-through conditions by reacting a freshly cleaved $(10 \overline{1} 4)$ calcite surface with two influent aqueous solutions containing $0.1 \mathrm{mM} \mathrm{CdCl}$ and $0.5 \mathrm{mM}$ $\mathrm{Na}_{2} \mathrm{CO}_{3}$, respectively, $(\Omega=475, \mathrm{pH}=8.2)$ for $4 \mathrm{~h}$ with a flow rate of $0.47 \mathrm{~mL} \mathrm{~min}^{-1}$. These growth conditions were selected to grow a cadmium carbonate epitaxial film as thick as possible in order for it to survive sample preparation for TEM analysis. Sample preparation for TEM analysis consisted of excising a thin cross section using a focus ion beam (FIB)-scanning electron microscope (SEM) instrument. In order to protect the sample from ion beam damage, a Pt layer approximately $200-400 \mathrm{~nm}$ thick was deposited first on the reacted calcite surface, followed by a 2- $\mu \mathrm{m} \mathrm{C}$ layer. The $\mathrm{Pt} / \mathrm{C}$ layer was thinned with a $\mathrm{Ga}$ beam followed by an Ar ion beam once the cross section was excised and placed on a TEM grid. The TEM analysis was performed with a FEI Titan 80-300 microscope operated at $300 \mathrm{kV}$. The instrument is equipped with a CEOS $\mathrm{GmbH}$ double-hexapole aberration corrector for the probe-forming lens, which allows for imaging with $0.1 \mathrm{~nm}$ resolution in scanning transmission electron microscopy mode (STEM). The images were acquired with a high angle annular dark field (HAADF) detector with inner collection angle set to $52 \mathrm{mrad}$.

\section{RESULTS}

\subsection{AFM}

\subsubsection{Cadmium-free aqueous solution}

Fig. 1 presents time-sequential images of the calcite $(10 \overline{1} 4)$ surface in contact with deionized water. The Cd-free control experiments were conducted to provide a reference for comparison with the Cd-bearing experiments and to determine the state of the surface at the point where $\mathrm{CdCl}_{2}$ is introduced. When the calcite crystal is in contact with deionized water, mostly shallow, mono-atomic etch pits form at the surface with a few deeper etch pits, as illustrated in Fig. 1. The mono-atomic etch pits and the uppermost layer of the deeper etch pits expand and these combine to lower the entire calcite surface, as described in the stepwave model (Lasaga and Luttge, 2001). The time-sequential AFM images in Fig. 1 indicate a progressive decrease in the calcite dissolution rate as the solution in the static fluid cell approaches saturation with respect to calcite. Indeed, in the time range of $30-390 \mathrm{~min}$, no etch pit formation is observed and the dissolution of the calcite cleavage surface takes place by the retreat of existing steps. The etch pits display a nearly rhombic shape, bounded by step edges 

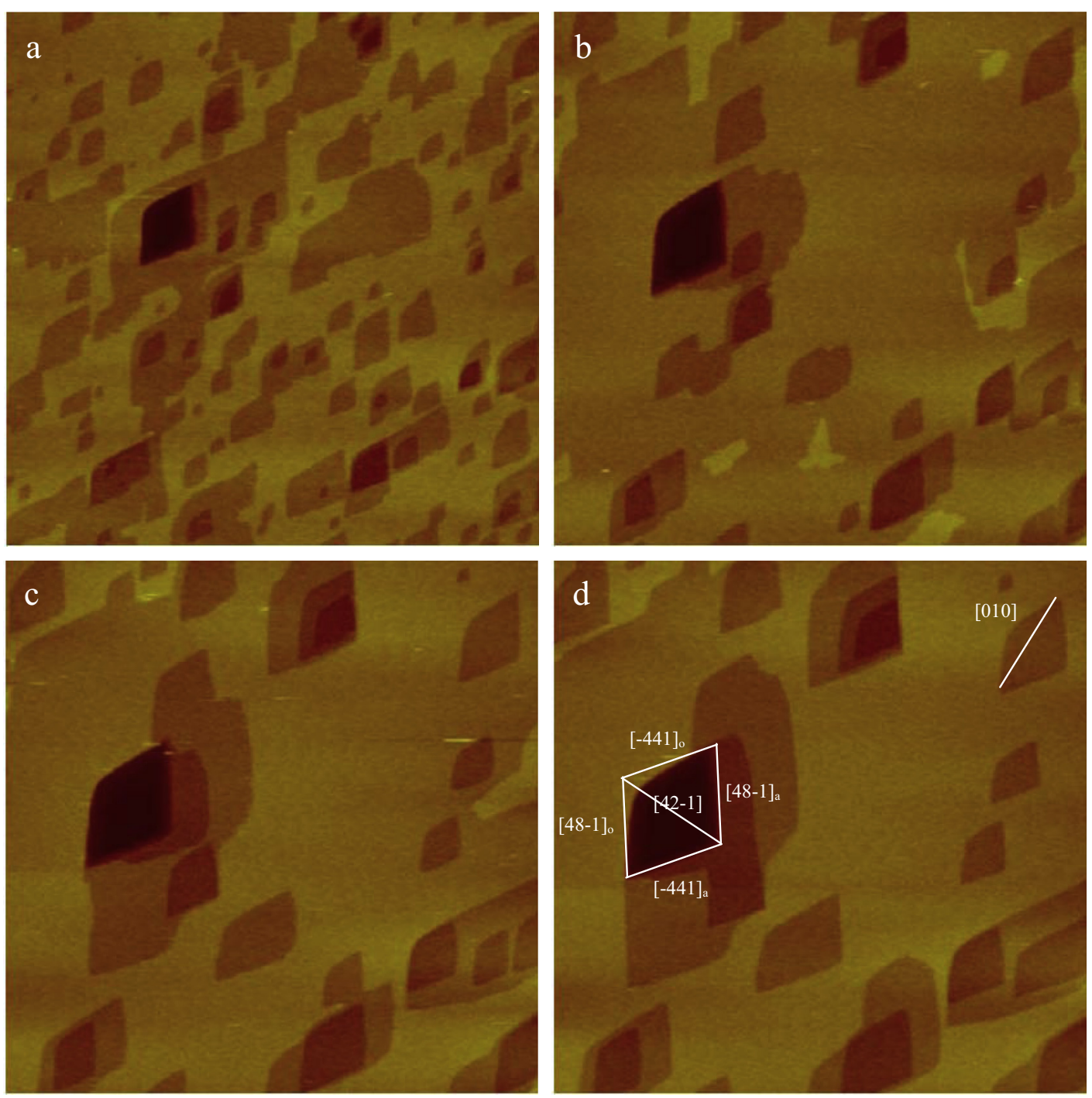

Fig. 1. Sequences of AFM topographic images $(6000 \mathrm{~nm} \times 6000 \mathrm{~nm})$ of calcite $(10 \overline{1} 4)$ surface in contact with deionized water. Images were taken at (a) $t=30 \mathrm{~min}$, (b) $t=150 \mathrm{~min}$, (c) $t=270 \mathrm{~min}$, (d) $t=390 \mathrm{~min}$ after introducing deionized water. These images show the expansion of etch pits with time.

oriented approximately along the $[48 \overline{1}]$ and $[\overline{4} 41]$ directions. There are two non-equivalent steps in the $[48 \overline{1}]$ and [441] directions, which intersect the calcite surface at obtuse and acute angles. The obtuse step pair, $[48 \overline{1}]_{\mathrm{o}}$ and $[\overline{4} 41]_{\mathrm{o}}$, and the acute step pair, $[48 \overline{1}]_{\mathrm{a}}$ and $[\overline{4} 41]_{\mathrm{a}}$, are bisected by a $c$-glide plane. The observed rounding of the obtuse-obtuse corners in Fig. 1 might be associated with trace impurities present in the system (Lea et al., 2001; Arvidson et al., 2003; Freij et al., 2005; Harstad and Stipp, 2007; Ruiz-Agudo et al., 2009).

\subsubsection{Cd-bearing aqueous solutions}

The surface features and etch pit expansion rates acquired at $\left[\mathrm{Cd}^{2+}\right]_{0}=0.001 \mathrm{mM}$ are similar to those in deionized water; however, significant morphology changes occur for $\left[\mathrm{Cd}^{2+}\right]_{0} \geqslant 0.002 \mathrm{mM}$. Two representative timesequential AFM image sets obtained in Cd-bearing aqueous solutions are presented in Figs. 2 and 3. Fig. 2a-e illustrate the progressive expansion of etch pits at $\left[\mathrm{Cd}^{2+}\right]_{0}=0.002$ $\mathrm{mM}$, accompanied by the nucleation and growth of precipitates on the surface. After exposure to $0.002 \mathrm{mM} \mathrm{Cd}^{2+}$, the etch pits formed on the calcite surfaces are bounded by curved steps. This observation is consistent with Chada et al. (2005) and Pérez-Garrido et al. (2007), who attributed the morphological change of etch pits to the adsorption of $\mathrm{Cd}^{2+}$ at step edges. The precipitates formed on the calcite surface exhibit a characteristic elongated shape, with the long axis following the $[42 \overline{1}]$ direction and the short axis parallel to [0 10] and a constant height of $2.2-2.7 \mathrm{~nm}$, which corresponds to $7-9 \mathrm{CdCO}_{3}$ monolayers based on the otavite $d$ spacing along the [104] direction. The constant height and preferential growth along $[42 \overline{1}]$ are in qualitative agreement with previous studies of the reaction of $\mathrm{Cd}$ - and Mn-bearing aqueous solutions with the (1014) calcite surface (Lea et al., 2003; Chada et al., 2005; Pérez-Garrido et al., 2007, 2009). The precipitates with a height of 

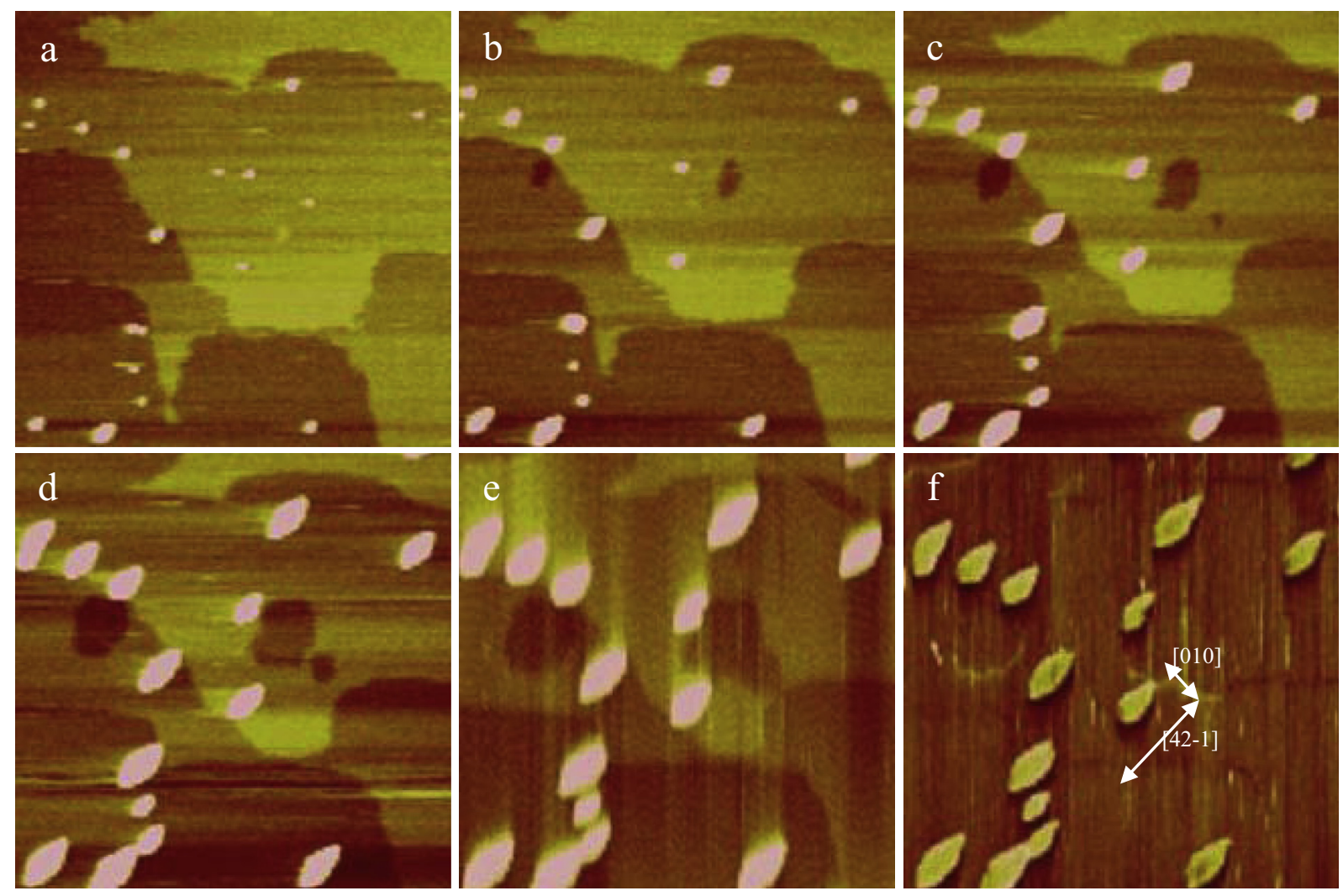

Fig. 2. Sequences of AFM topographic images $(4000 \mathrm{~nm} \times 4000 \mathrm{~nm})$ of calcite $(10 \overline{1} 4)$ surface in contact with Cd-bearing solution with initial $\left[\mathrm{Cd}^{2+}\right]=0.002 \mathrm{mM}$. Images (a) to (e) show the expansion of etch pits and the growth of 3D islands with time. Time interval is 50 min. Image (f), which was obtained at the same time as (e), is a lateral force microscopy (LFM) image that shows different friction of the overgrowth and the substrate.

2.2-2.7 $\mathrm{nm}$ are referred to as three-dimensional (3D) islands hereafter, following Chernov (1984) and Pérez-Garrido et al. (2007). Fig. 2f presents a lateral force microscopy (LFM) image scanned in the trace direction. It is obvious that the islands display a different lateral deflection signal than that of the calcite surface, with the brighter regions in Fig. $2 \mathrm{f}$ corresponding to higher friction. Although qualitative, the higher friction of the $3 \mathrm{D}$ islands is consistent with the overgrowing phase having a different chemical composition from the calcite substrate. The growth of the $3 \mathrm{D}$ islands proceeds by lateral advancement in the $[42 \overline{1}]$ and [010] directions. Due to the lack of well-defined straight edges, the growth kinetics of the 3D islands are described by the variations in island length and width over time, $V_{[42 \overline{1}]}$ and $V_{[010]}$, respectively.

$3 \mathrm{D}$ islands form on the surface in the range $0.002 \leqslant\left[\mathrm{Cd}^{2+}\right]_{0} \leqslant 0.050 \mathrm{mM}$ but, as $\left[\mathrm{Cd}^{2+}\right]_{0}$ further increases, the formation of nuclei with a nearly rhombic 2D morphology becomes significant, as shown in Fig. 3 for $\left[\mathrm{Cd}^{2+}\right]_{0}=0.050 \mathrm{mM}$. The $2 \mathrm{D}$ nuclei have a height of approximately $3 \AA$, which is consistent with the expected height of an otavite monolayer. It should be noted that calcite and otavite have very similar $d$ spacings along the [104] direction (3.14 and $3.07 \AA$, respectively). While the 2D nuclei spread and coalesce on the surface, the existing etch pits shrink and eventually close. Growth is observed to be dominated by the spreading of monolayers at $\left[\mathrm{Cd}^{2+}\right]_{0}>0.050 \mathrm{mM}$. The summed speed of two parallel steps along [48 $\overline{1}]$ or $[\overline{4} 41], V_{\text {sum }}=V_{\text {obtuse }}+V_{\text {acute }}$ was calculated by measuring the changes in distance between these parallel steps in time-sequential images. The rates of etch pit closure and 3D islands and 2D nuclei growth are plotted as a function of the initial $\mathrm{CdCl}_{2}$ concentration in Fig. $4 \mathrm{a}-\mathrm{c}$.

Fig. 4a presents $V_{\text {sum }}$ obtained for etch pits where negative rates refer to the expansion of etch pits (i.e., calcite dissolution) while positive rates represent their shrinking (i.e., growth). In our AFM experiments, it takes 5-8 min to collect one image, and thus we miss the first 10 min of reaction due to the time for instrument adjustment and image scanning. Fig. 5 demonstrates the variation in the distance between two parallel [48 $\overline{1}]$ or $[\overline{4} 41]$ steps over time for etch pit expansion and closure. Over the period of 17-100 min after introducing deionized water, $V_{\text {sum }}$ is $0.03 \mathrm{~nm} \mathrm{~s}^{-1}$ in the cadmium-free experiments (solid line in Fig. 5), which is two orders of magnitude lower than the typical value obtained in flow-through studies (Liang et al., 1996). This difference is associated with the solution chemistry. Indeed, compared to flow-through experiments in which calcite is always in contact with pure water, the aqueous solution approaches saturation with respect to calcite in our static fluid cell. ICP-OES and pH measurements after 30 and $80 \mathrm{~min}$ yielded saturation state values of $\Omega=0.11$ and 


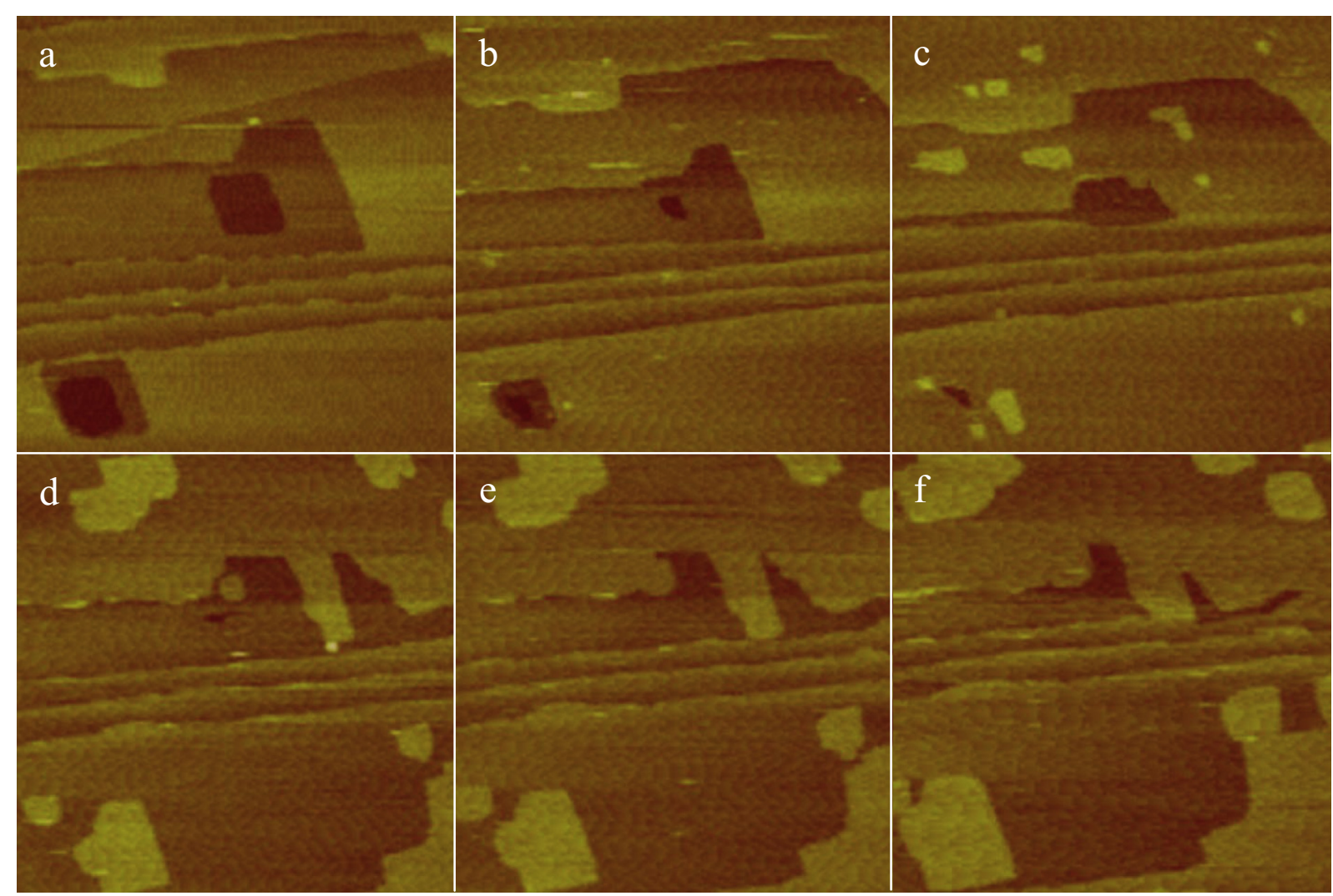

Fig. 3. Sequences of AFM topographic images $(3000 \mathrm{~nm} \times 3000 \mathrm{~nm}$ ) of calcite $(10 \overline{1} 4)$ surface in contact with Cd-bearing solution with initial $\left[\mathrm{Cd}^{2+}\right]=0.050 \mathrm{mM}$. Images were taken at (a) $t=0 \mathrm{~min}$, (b) $t=43 \mathrm{~min}$, (c) $t=60 \mathrm{~min}$, (d) $t=150 \mathrm{~min}$, (e) $t=240 \mathrm{~min}$, (f) $t=330 \mathrm{~min}$. These images show the etch pit shrinking and the monolayer growth with time.

$\Omega=0.16$, respectively. This decreases the driving force for calcite dissolution, corresponding to a much slower dissolution rate. In the presence of $\mathrm{Cd}^{2+}$ in the aqueous solution, $V_{\text {sum }}$ decreases from 0.03 to $0.01 \mathrm{~nm} \mathrm{~s}^{-1}$ as $\left[\mathrm{Cd}^{2+}\right]_{0}$ increases from 0 to $0.005 \mathrm{mM}$ (Fig. 4a), indicating the inhibitory effects of $\mathrm{Cd}^{2+}$ on calcite dissolution. At $\left[\mathrm{Cd}^{2+}\right]_{0}=0.010 \mathrm{mM}$, steps cease to migrate. As $\left[\mathrm{Cd}^{2+}\right]_{0}$ further increases, the direction of the step motion reverses and the etch pits start to close. An example of the progressive etch pit closure is shown in Fig. 5 for $\left[\mathrm{Cd}^{2+}\right]_{0}=0.050 \mathrm{mM}$. The etch pit closing rate increases linearly with $\left[\mathrm{Cd}^{2+}\right]_{0}$ in the concentration range considered in this work (Fig. 4a).

The spreading rates of the $3 \mathrm{D}$ islands along the $[42 \overline{1}]$ and $[010]$ directions are illustrated in Fig. $4 \mathrm{~b}$ as a function of $\left[\mathrm{Cd}^{2+}\right]_{0}$. At all concentrations, the islands grow approximately three times faster in the $[42 \overline{1}]$ direction than in the $[010]$ direction, leading to their elongated shapes. Growth rates along both directions increase with increasing $\left[\mathrm{Cd}^{2+}\right]_{0}$; however, the slope of the growth rate versus $\left[\mathrm{Cd}^{2+}\right]_{0}$ curve is steeper for $0.002 \mathrm{mM} \leqslant\left[\mathrm{Cd}^{2+}\right]_{0} \leqslant 0.01 \mathrm{mM}$ than for $0.01 \mathrm{mM} \leqslant\left[\mathrm{Cd}^{2+}\right]_{0} \leqslant 0.05 \mathrm{mM}$. Fig. 6 illustrates the variations in height over time for representative islands at several initial $\mathrm{Cd}^{2+}$ concentrations. After an initial stage during which growth occurs both laterally and vertically, the $3 \mathrm{D}$ islands reach a height of $2.2-2.7 \mathrm{~nm}$, which remains constant over our entire experimental time $(2-6 \mathrm{~h})$. Final heights are independent of the initial concentration of $\mathrm{Cd}^{2+}$ in the solution. In some experiments, we may miss the initial stage of lateral and vertical growth due to the time required for instrument adjustment and image scanning.

Fig. $4 \mathrm{c}$ presents the monolayer growth rates. Generally speaking, the 2D growth rate increases slowly with $\left[\mathrm{Cd}^{2+}\right]_{0}$ at low supersaturation and then more rapidly at high $\left[\mathrm{Cd}^{2+}\right]_{0}$. Unlike the 3D islands, the growth rates of 2D nuclei are comparable in the $[42 \overline{1}]$ and $[010]$ directions, corresponding to a nearly rhombic shape, as illustrated in Fig. 3. At the same concentration of $\mathrm{Cd}^{2+}, 2 \mathrm{D}$ nuclei grow slower than both the 3D islands and the etch pits.

\subsubsection{Mixed CalCd-bearing aqueous solutions}

The heteroepitaxial nucleation and growth of a new phase on the calcite $(10 \overline{1} 4)$ surface in contact with Cdbearing aqueous solutions has been reported in the literature (Stipp et al., 1992; Chiarello and Sturchio, 1994; Chiarello et al., 1997; Hay et al., 2003; Chada et al., 2005; Pérez-Garrido et al., 2007; Cubillas and Higgins, 2009). However, uncertainties remain regarding its exact composition as a function of growth conditions. A recent AFM study of $\mathrm{Cd}^{2+}$-calcite interaction under static experimental conditions (Pérez-Garrido et al., 2007) proposed that the $3 \mathrm{D}$ islands formed on calcite surfaces were almost pure $\mathrm{CdCO}_{3}$ for $0.005 \leqslant\left[\mathrm{Cd}^{2+}\right]_{0} \leqslant 0.05 \mathrm{mM}$ based on 

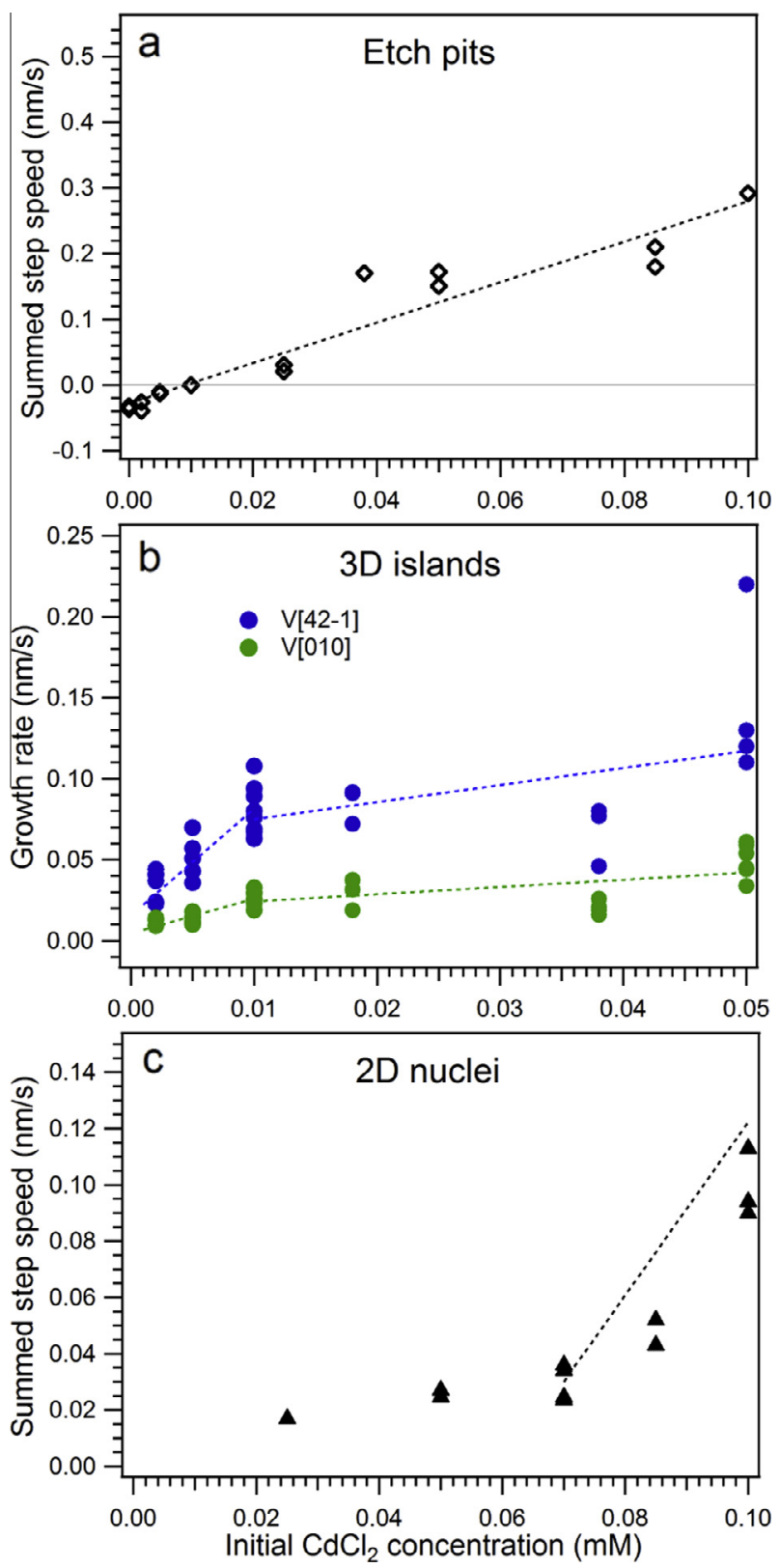

Fig. 4. Growth rates of $\mathrm{CdCO}_{3}$ on calcite $(10 \overline{1} 4)$ surfaces as a function of initital $\left[\mathrm{Cd}^{2+}\right]$. (a) Etch pit closing (+) or expanding (-) rates: black diamonds represent the summed speeds of two parallel [48 $\overline{1}]$ or $[\overline{4} 41]$ steps $\left(V_{\text {sum }}=V_{\text {obtuse }}+V_{\text {acute }}\right)$, dashed line represents the linear fit. (b) Growth rates of 3D islands measured along [42 $\overline{1}]$ (blue circles) and [010] directions (green circles). Dashed lines are hand drawn to demonstrate the slope changes in plots. (c) 2D monolayer growth rates: black triangles represent the summed speeds of two parallel [48 $\overline{1}]$ or $[\overline{4} 41]$ steps, dashed line has the same slope as the line in (a). (For interpretation of the references to color in this figure legend, the reader is referred to the web version of this article.)

thermodynamic considerations. As noted in that study, although non-ideal mixing of calcite and otavite has been reported (Rock et al., 1994), the majority of the data published in the literature to date (Davis et al., 1987;

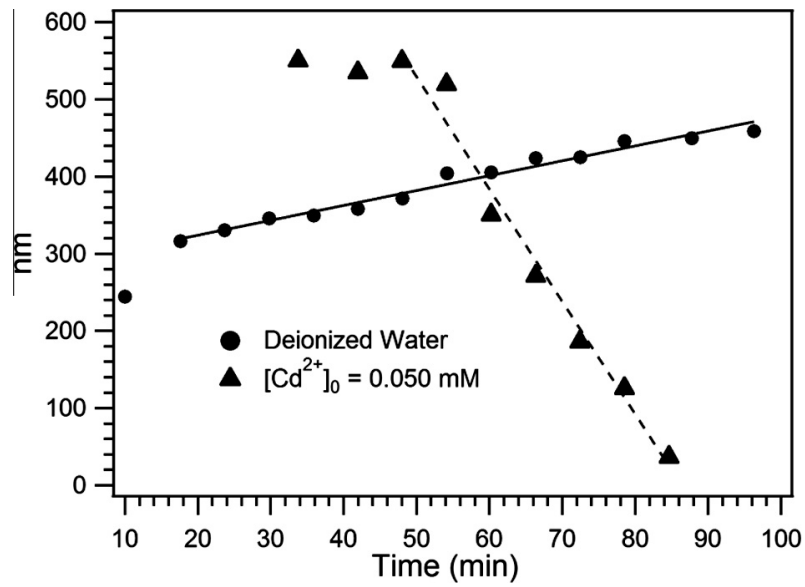

Fig. 5. Etch pit expansion and closure over time in deionized water (shown in circles) and aqueous solution with $\left[\mathrm{Cd}^{2+}\right]_{0}=0.050 \mathrm{mM}$ (shown in triangles). Solid and dashed lines represent linear fits.

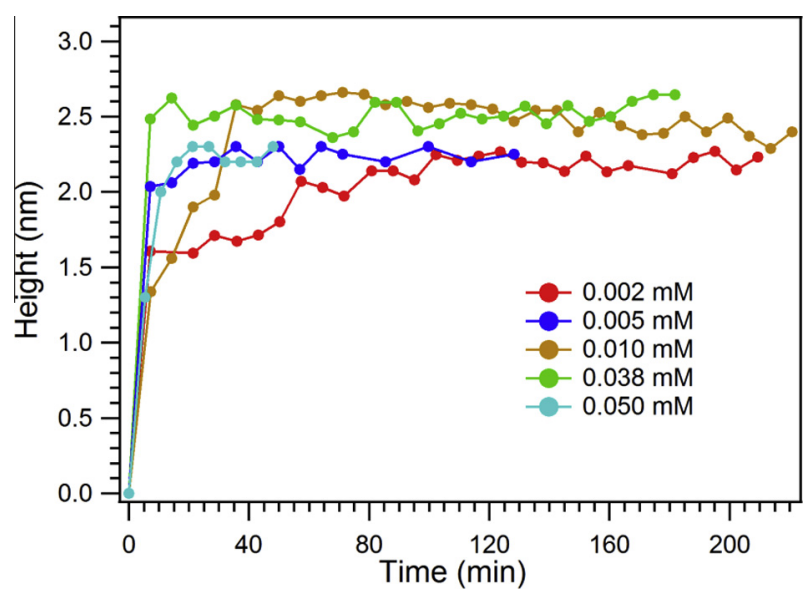

Fig. 6. Height of 3D islands growing on calcite $(10 \overline{1} 4)$ surface as a function of time.

Königsberger et al., 1991; Stipp et al., 1992; Tesoriero and Pankow, 1996) suggests close to ideal mixing and, therefore, ideal mixing was assumed by Pérez-Garrido et al. (2007). Pérez-Garrido et al. (2007) explained that, due to the significant difference in solubility between calcite and otavite, the molar fraction of the $\mathrm{CdCO}_{3}$ component of the $3 \mathrm{D}$ islands would be greater than 0.97 in their experiments, according to the maximum of the stoichiometric saturation function (Prieto et al., 1993):

$\beta(x)=\frac{a_{\mathrm{Cd}^{2+}}^{x} a_{\mathrm{Ca}^{2+}}^{(1-x)} a_{\mathrm{CO}_{3}^{2-}}}{\left(K_{\mathrm{sp}}^{\text {otavite }} X_{\mathrm{CdCO}_{3}} \gamma_{\mathrm{CdCO}_{3}}\right)^{x}\left(K_{\mathrm{sp}}^{\text {calcite }} X_{\mathrm{CaCO}_{3}} \gamma_{\mathrm{CaCO}_{3}}\right)^{(1-x)}}$

where $X_{\mathrm{CdCO}_{3}}$ and $X_{\mathrm{CaCO}_{3}}$ are the molar fractions of the cadmium and calcium carbonate components in the solid solution and $\gamma_{\mathrm{CdCO}_{3}}$ and $\gamma_{\mathrm{CaCO}_{3}}$ are the activity coefficients of these components, which are taken to be unity as an ideal solid solution is assumed. With similar initial concentrations of $\mathrm{Cd}^{2+}$, we would expect the formation of extremely 
Cd-rich coatings on calcite in our experiments, with $X_{\mathrm{CdCO}_{3}}$ ranging from 0.98 to 1.00 .

One limitation of predicting the composition of the coating phase solely based on Eq. (2) is that it does not include any energy contribution that might favor the incorporation of calcium in the growing coating to release epitaxial strain. In addition, Eq. (2) follows from equilibration of the aqueous solution with a calcite-otavite solid solution of a given composition; but thermodynamic equilibrium is rarely achieved during the growth process in our experiments. Indeed, our ICP-OES results and $\mathrm{pH}$ measurements indicate an $\Omega_{\text {otavite }}$ of $0.3-26$ and a $\mathrm{pH}$ of 7.4-8.4 after reaction, which differ from what is expected based on equilibrium conditions. It is thus possible that the composition of the epitaxial phase is determined by a combination of thermodynamic and kinetic factors.

To verify the thermodynamic prediction of almost pure otavite growth on calcite, one indirect approach is to conduct AFM experiments by adding $\mathrm{Ca}^{2+}$ to the aqueous solution. Fig. 7 illustrates the growth rates of $3 \mathrm{D}$ islands as a function of $\mathrm{Ca}^{2+}$ added to the aqueous solution with an initial $\left[\mathrm{Cd}^{2+}\right]$ of $0.050 \mathrm{mM}$. If both $\mathrm{Cd}^{2+}$ and $\mathrm{Ca}^{2+}$ were precipitate constituents, one would expect that both $\mathrm{Cd}^{2+}$ and $\mathrm{Ca}^{2+}$ in sufficient quantities would be necessary for the optimum growth rate. In other words, the addition of $\mathrm{Ca}^{2+}$ to Cd-bearing aqueous solution would enhance the growth rate of the overgrowing phase on the calcite surface. This is obviously not the case according to our experimental results. As shown in Fig. 7, the growth rates of the $3 \mathrm{D}$ islands on calcite surfaces decrease with increasing concentration of $\mathrm{Ca}^{2+}$ in the [42 $\overline{1}$ ] and [010] directions. Moreover, the AFM images do not show any significant changes in island morphology (images not shown), which could be expected if calcium was increasingly incorporated in the $3 \mathrm{D}$ islands to release strain in these added $\mathrm{Ca}^{2+}$ experiments. The inhibitory effect of $\mathrm{Ca}^{2+}$ on island growth is in accord with the presumed negligible amount of $\mathrm{Ca}^{2+}$ in the overgrowing phase and could be due to calcium reducing cadmium access to surface sites. Therefore, we refer to the coating phase as cadmium carbonate hereafter.

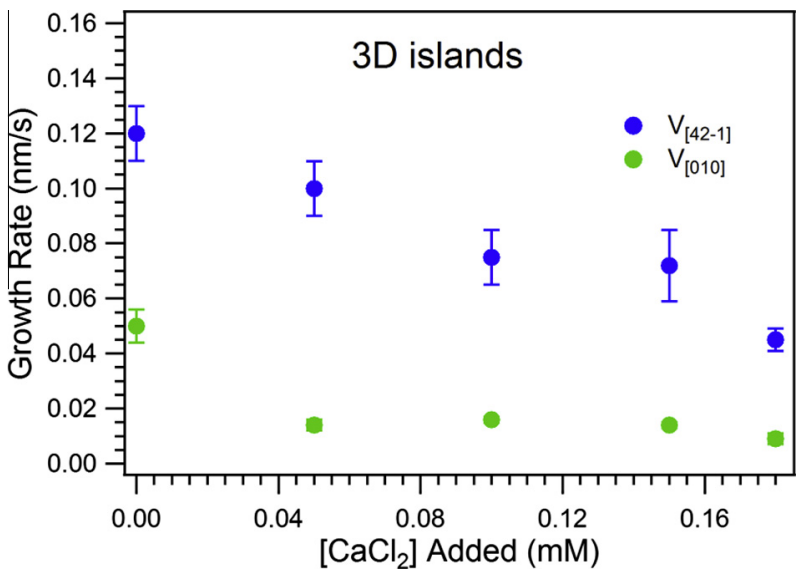

Fig. 7. Growth rates of $3 \mathrm{D}$ islands along the $[42 \overline{1}]$ and $[010]$ directions as a function of $\left[\mathrm{Ca}^{2+}\right]$ at $\left[\mathrm{Cd}^{2+}\right]_{0}=0.05 \mathrm{mM}$.

\subsection{TEM}

A thick cadmium carbonate epitaxial film was grown on the calcite surface by flowing through $0.1 \mathrm{mM} \mathrm{CdCl}_{2}$ and $0.5 \mathrm{mM} \mathrm{Na} \mathrm{CO}_{3}$ aqueous solutions for $4 \mathrm{~h}$. Although these growth conditions differ from those used in the AFM experiments because of the need to ensure that the epitaxial film would survive sample preparation, they do provide valuable information on the atomic-level structure of the interface between the calcite substrate and the epitaxial film. Fig. 8 shows that perfect epitaxial growth can be achieved over tens of nanometers in these conditions. In the STEM HAADF images, brightness is proportional to $Z^{1.7-1.9}$ (where $Z$ is the atomic number) so that cadmium carbonate appears much brighter than calcium carbonate. Both calcite and otavite are highly beam sensitive. Consequently, dark spots can be seen in the calcite substrate and the epitaxial film due to electron beam damage. In addition, large-scale images showed damage due to the FIB sample preparation near the top of the epitaxial film and some heterogeneities due to the epitaxial film not being fully continuous over the scale of hundreds of nanometers.

Fig. 8a reveals that atomically-sharp interfaces can form on flat calcite terraces and Fig. $8 \mathrm{~b}$ and $\mathrm{c}$ indicate that epitaxial growth can also take place around surface roughness with, for example, otavite growing around a protruding surface feature (Fig. 8b) or filling a trough in the surface (Fig. 8c). None of the images taken showed evidence of dislocations indicating that the strain induced in the epitaxial film due to the lattice mismatch can simply be accommodated by atomic displacements. The fact that an epitaxial film tens of nanometers thick was able to grow without any visible dislocations suggests that the growth of otavite on calcite is not strain limited, provided a sufficient saturation level is sustained. Although the growth conditions were different, the TEM images suggest that the 3D islands observed in the AFM experiments could be generally free of dislocations with a fully epitaxial structure.

\section{DISCUSSION}

\section{1. $\left[\mathrm{Cd}^{2+}\right]$-dependent heteroepitaxial growth mechanisms}

Heteroepitaxial growth follows three different mechanisms in our experiments: advancement of existing steps (in etch pits or on terraces), growth of 3D islands, and expansion of $2 \mathrm{D}$ nuclei. Both the expansion of $2 \mathrm{D}$ nuclei and the advancement of etch pit step edges are monolayer growth. However, they start to grow at different critical $\mathrm{Cd}^{2+}$ concentrations: $0.010 \mathrm{mM}$ for the etch pits and $0.025 \mathrm{mM}$ for 2D nuclei (Fig. 4), corresponding to supersaturations of 56 and 117 , respectively. The existence of a threshold supersaturation for 2D nucleation is a common phenomenon in single-phase crystal growth (Teng et al., 2000) and has also been observed in experiments of (Mn, $\mathrm{Ca}) \mathrm{CO}_{3}$ growth on calcite (Astilleros et al., 2006) and (Ba, $\mathrm{Sr}$ ) $\mathrm{SO}_{4}$ growth on barite (Pina et al., 2000). In pure calcite growth (Teng et al., 2000), 2D nucleation occurs as solution supersaturation exceeds 2.2, where the driving force is high enough to overcome the free energy barrier 


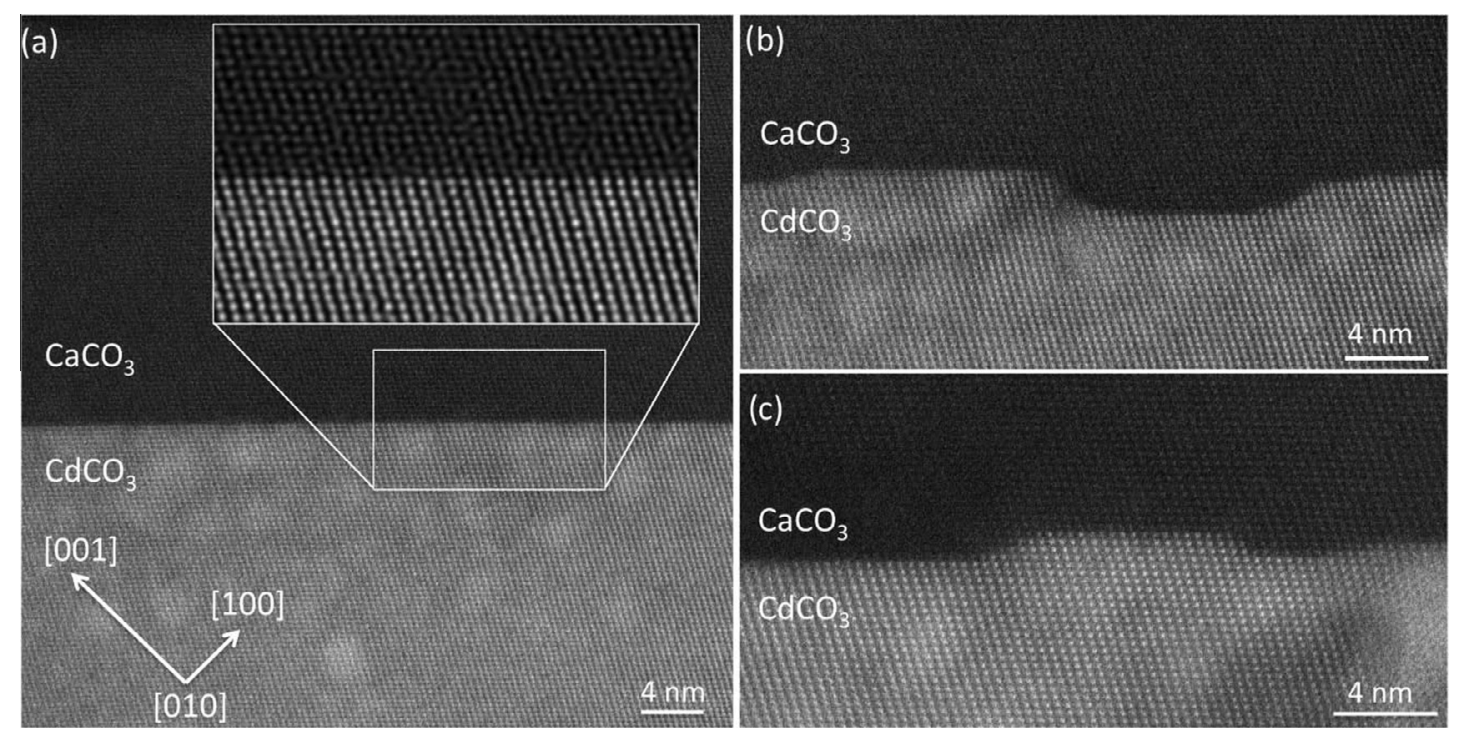

Fig. 8. HAADF STEM images of the interface between the calcium carbonate substrate (dark) and the cadmium carbonate epitaxial film (bright) obtained on the [0 10] zone axis; (a) HAADF-STEM image of epitaxial growth on a flat calcite terrace (inset is a probe deconvoluted image highlighting the lattice matching between the film and the substrate); and (b) and (c) STEM images of epitaxial growth in rough regions of the surface. The dark regions in the substrate and the epitaxial film are due to electron beam damage.

for 2D nucleation (De Yoreo and Vekilov, 2003). In this work, the critical $\left[\mathrm{Cd}^{2+}\right]_{0}$ for etch pit closing is lower than that for $2 \mathrm{D}$ nucleation, which can be interpreted in terms of the existence of a free energy barrier for nucleation. That is, the advancement of existing steps does not involve the nucleation process and therefore does not need to overcome the free energy barrier for 2D nucleation. Interestingly, in the case of pure calcite growth, supersaturation has to exceed 2.2 for $2 \mathrm{D}$ nucleation to take place, while the critical supersaturation is 117 for $2 \mathrm{D}$ nucleation of otavite on calcite, according to our experimental results. This large difference implies that growth via heteroepitaxy significantly shifts the level of supersaturation required for the transition between the two mechanisms to occur. Additionally, the critical supersaturation for 2D nucleation can be correlated to mineral solubility whereby higher critical supersaturations are required for minerals with low solubilities (De Yoreo and Vekilov, 2003). This effect stems from the fact that $2 \mathrm{D}$ nucleation requires the creation of step edges, which means that the free energy barrier for 2D nucleation increases with increasing step edge energy, and that a lower solubility translates to a higher step edge energy (Christoffersen et al., 1991) as well as a lower equilibrium kink density (De Yoreo et al., 2009). This effect is likely to also contribute to the large difference in critical supersaturations between pure calcite growth and otavite growth on calcite.

One striking finding of the present study is the growth of the heteroepitaxial phase via the nucleation and expansion of $3 \mathrm{D}$ islands at lower supersaturation levels than required for both 2D nucleation and advancement of etch pit steps. This growth mechanism is not observed for pure calcite growth and, importantly, contradicts at first glance the free energy barrier argument discussed above. To better understand this growth mechanism, Fig. 9 shows information on the growth of a single representative island, including the variations in height, length, and width of the island and the height profiles at different stages of growth. Note that the $x$ and $y$ axis have different scales in the height profiles and that, therefore, the island's sides actually form a very low angle with the calcite surface.

During the initial stage of reaction, the island grows both vertically and laterally, and the lateral growth rates are similar along [42 1$]$ and [010]. As growth proceeds, the island exhibits a flat top, parallel to the $(10 \overline{1} 4)$ orientation, as demonstrated in the height profiles. Once the upper (1014) surface of $\mathrm{CdCO}_{3}$ has formed, the vertical growth ceases and the 3D island grows by spreading laterally only, with the growth preferentially occurring in the $[42 \overline{1}]$ direction compared to the $[010]$ direction. We hypothesize that, in the case of low $\left[\mathrm{Cd}^{2+}\right]_{0}$, the supersaturation is not sufficiently high to form crystalline surface nuclei directly. Instead, a $\mathrm{CdCO}_{3}$ precursor, which is not fully crystalline, forms in the early stage of reaction represented by the first few points in Fig. 9. This precursor acts as a seed or a nucleation substrate that transforms to a more stable crystalline phase, characterized by the flat $(10 \overline{1} 4)$ top surface that emerges at fixed average height within approximately $1 \mathrm{~h}$ (Fig. 9) and the direction-dependent growth rates. It is also possible that this precursor could be a hydrated form of cadmium carbonate that dehydrates upon adopting the calcite structure, as it has been shown for the formation of magnesite $\left(\mathrm{MgCO}_{3}\right)$ produced via forsterite $\left(\mathrm{Mg}_{2} \mathrm{SiO}_{4}\right)$ carbonation reaction (Kwak et al., 2010, 2011). Once the island has fully crystallized and adopts the calcite structure, it does not grow further in height within the timescale of our experiments, which is consistent with expectation that the most stable surface of a given mineral (here the (1014) surface for calcite) grows the slowest. Non-classical pathways of crystallization via the formation of amorphous 


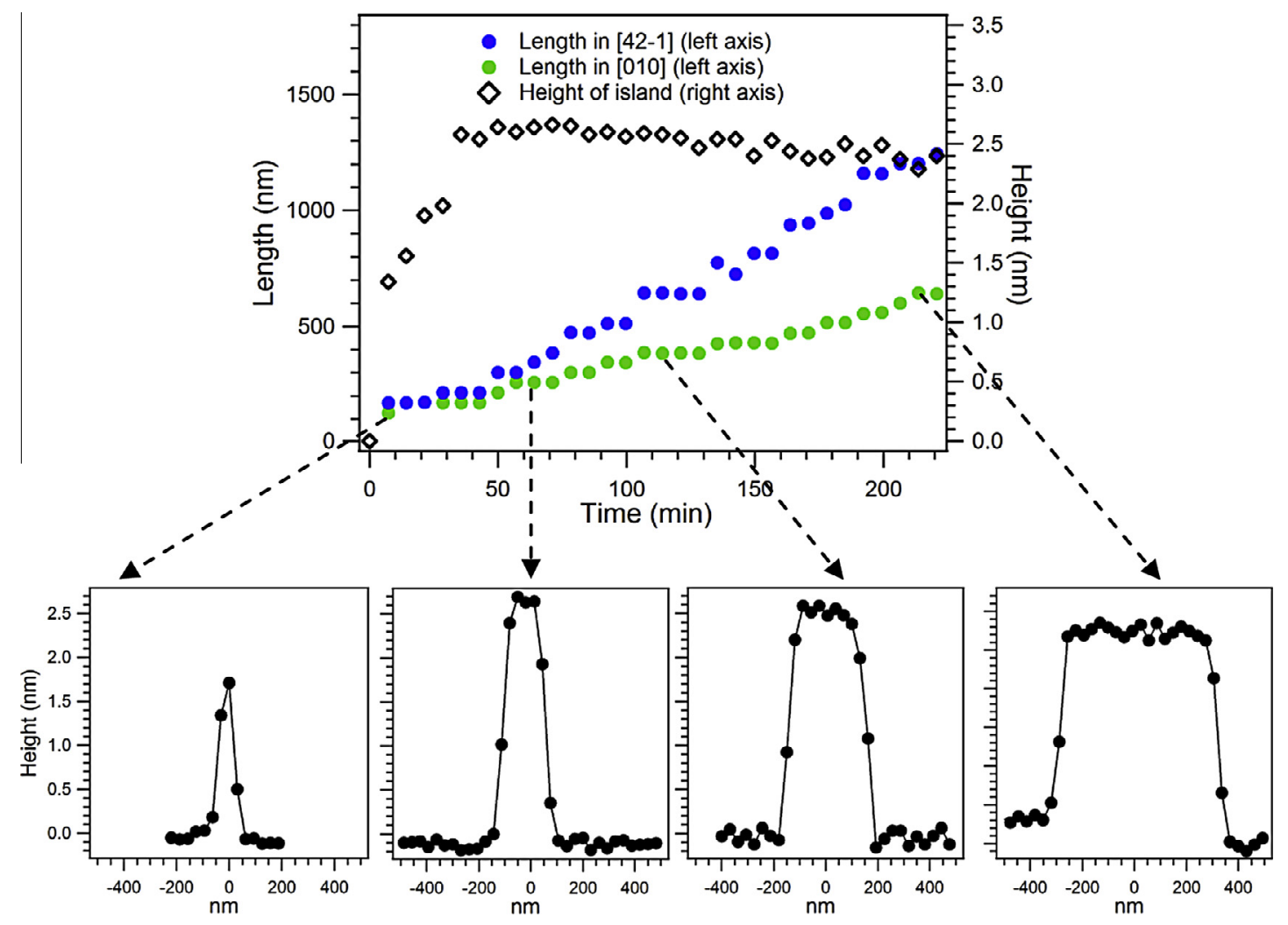

Fig. 9. Length (blue circles), width (green circles), and height (black diamonds) of a representative island growing over time. The island was obtained on calcite $(10 \overline{1} 4)$ surface in contact with $\left[\mathrm{Cd}^{2+}\right]_{0}=0.010 \mathrm{mM}$. Height profiles at the intial and late stages of growth are also shown. (For interpretation of the references to color in this figure legend, the reader is referred to the web version of this article.)

precursors have been reported, for example, for growth of biogenic calcite in the presence of a calcite seed crystal (Weiner et al., 2005; Politi et al., 2008; Killian et al., 2009), for calcite growth templated by self-assembled monolayers (Freeman et al., 2008; Pouget et al., 2009), and for homogeneous nucleation and growth of calcite in aqueous solutions (Gebauer et al., 2008; Meldrum and Sear, 2008; Raiteri and Gale, 2011). This idea is also supported by the Ostwald-Lussac law of phases, which states that the free energy barrier for nucleation leading to a more disordered state is less than the one leading to a more crystalline state (Nancollas, 1982).

In the present study, the $3 \mathrm{D}$ islands spread laterally along $[42 \overline{1}]$ and $[010]$ directions rather than the $[\overline{4} 41]$ and $[48 \overline{1}]$ directions, which are the directions predicted by the periodic bond chain model (Paquette and Reeder, 1995; Jordan et al., 2001). The preferential growth in the [42 $\overline{1}]$ direction and the consequent elongated morphology of the islands have been attributed to the elastic properties of the overgrowth, i.e. $[42 \overline{1}]$ is the direction of lowest elastic modulus in the (1014) plane (Lea et al., 2003; PérezGarrido et al., 2007, 2009). The kinetic effect of kink sites might also contribute to the elongated shape of the islands (Lea et al., 2003; Pérez-Garrido et al., 2007). It is possible that slow attachment rates at obtuse-acute kink sites lead to a slow growth along $[010]$ and result in elongation of the islands along $[42 \overline{1}]$. Unlike the $3 \mathrm{D}$ islands, the monolayer growth proceeds by advancement $[\overline{4} 41]$ and [48 $\overline{1}]$ step edges. Being crystalline from the time of nucleation, the 2D nuclei have a strong propensity to adopt a specific shape dictated by the atomic structure of the substrate. The small misfit ( $4 \%$ ) between the epitaxial cadmium carbonate phase and the calcite substrate gives rise to overgrowth step heights and atomic lattices that are indistinguishable from the substrate. As illustrated in Fig. 3, the monolayers of otavite formed on calcite exhibit a step height of approximately $3 \AA$ and a rhombic shape surrounded by step edges approximately along $[\overline{4} 41]$ and $[48 \overline{1}]$, representing the rhombohedral symmetry of the otavite and calcite lattices.

The observations made in this work are consistent with previous studies on cadmium carbonate growth at calcite surfaces. Pérez-Garrido et al. (2007) observed 3D island nucleation and growth at $\left[\mathrm{Cd}^{2+}\right]=0.005-0.025 \mathrm{mM}$ under static conditions with non-buffered solutions, as we did in our experiments. Only at $\left[\mathrm{Cd}^{2+}\right]=0.05 \mathrm{mM}$ did the authors report the formation of a $\mathrm{CdCO}_{3}$ monolayer on the calcite surface followed by $3 \mathrm{D}$ island growth on this monolayer. We observed simultaneous growth of islands and monolayers in our experiments at this concentration; however, we did not systematically find the islands to grow on the monolayers. Therefore, we conclude that the observation made by Pérez-Garrido et al. (2007) is more likely due to a combination of two growth mechanisms occurring simultaneously rather than the epitaxial phase following the Stranski-Krastanov growth mechanism (i.e., island growth atop a wetting layer). Hay et al. (2003) observed the forma- 
tion of "single-layer and multi-layer islands" on calcite surfaces exposed to aqueous solutions containing $0.1 \mathrm{mM}$ $\mathrm{Cd}^{2+}$ and with their $\mathrm{pH}$ adjusted to 8.4. Although Hay et al. also use the term "islands", it appears from their description and AFM images that they are referring to monolayer growth whereby new monolayer nuclei can form and expand on top of existing monolayers, i.e. layerby-layer growth. Cubillas and Higgins (2009) also reported layer-by-layer growth on calcite surfaces at this same cadmium concentration but from flow-through experiments with $\mathrm{pH}$ ranging from 8.0 to 8.5. Layer-by-layer growth was also observed in our static, non-buffered experiments for this cadmium concentration. Therefore, this work shows that differences in growth mechanisms observed in previous studies were principally related to the initial $\mathrm{Cd}$ aqueous concentration rather than differences in growth conditions (e.g., static versus flow-through conditions).

\subsection{Growth kinetics as a function of $\left[\mathrm{Cd}^{2+}\right]$}

The $3 \mathrm{D}$ island growth rates versus $\left[\mathrm{Cd}^{2+}\right]_{0}$ shows a slope change at $\left[\mathrm{Cd}^{2+}\right]_{0}=0.010 \mathrm{mM}$ (Fig. $4 \mathrm{~b}$ ), which could be explained by the dissolution and growth of existing steps and the competitive $2 \mathrm{D}$ nuclei growth process. At $\left[\mathrm{Cd}^{2+}\right]_{0}<0.010 \mathrm{mM}$, dissolution of calcite continues after exposure to Cd-bearing solutions, as indicated by the negative rates in Fig. 4a, providing a source of $\mathrm{CO}_{3}^{2-}$ ions for the growth of the new otavite phase. Under this situation, $\mathrm{Cd}^{2+}$ inhibits dissolution through blocking of kink sites and contributes to the $3 \mathrm{D} \mathrm{CdCO}_{3}$ growth. When $\left[\mathrm{Cd}^{2+}\right]_{0}$ further increases, calcite dissolution stops and growth of the existing steps (pit closing) starts, consuming rather than supplying $\mathrm{CO}_{3}^{2-}$. This gives rise to a slope decrease for $\left[\mathrm{Cd}^{2+}\right]_{0} \geqslant$ $0.010 \mathrm{mM}$ compared to $0.002 \mathrm{mM} \leqslant\left[\mathrm{Cd}^{2+}\right]_{0} \leqslant 0.010 \mathrm{mM}$, as shown in Fig $4 \mathrm{~b}$. This is consistent with the observation, previously reported in the literature for calcite growth, that the calcite step velocities and, more generally, the calcite growth rate decrease as the calcium-to-carbonate ratio increases (Nehrke et al., 2007; Larsen et al., 2010; Stack and Grantham, 2010; Bracco et al., 2012; Gebrehiwet et al., 2012). Additionally, the growth of 2D nuclei takes place at $\left[\mathrm{Cd}^{2+}\right]_{0} \geqslant 0.025 \mathrm{mM}$ (Fig. 4c), competing for $\mathrm{Cd}^{2+}$ and $\mathrm{CO}_{3}^{2-}$ in the solution, which could also contribute to the low slope at high $\left[\mathrm{Cd}^{2+}\right]_{0}$ for $3 \mathrm{D}$ island growth.

The expansion of 2D nuclei and the advancement of etch pit step edges behave differently. The advancement rate of etch pit step edges increases linearly with increasing $\left[\mathrm{Cd}^{2+}\right]_{0}$ over the whole concentration range (Fig. 4a), whereas a slope change is observed in the plot for $2 \mathrm{D}$ nuclei growth kinetics (Fig. 4c). The different kinetic behaviors exhibited by etch pits and 2D nuclei could be interpreted in terms of kink density. It is well accepted that the growth process proceeds by the attachment of growth units to the growing crystal and that the attachment occurs predominantly at kink sites. If it is assumed that steps have a high density of kinks and that step propagation is limited only by the kinetics of solute attachment and detachment at kink sites, the rate of step advancement is predicted to be linearly proportional to the difference between the actual and equilibrium concentrations of the solute, $\left(C-C_{\mathrm{e}}\right)$, by (Teng et al., 1999; De Yoreo and Vekilov, 2003; De Yoreo et al., 2009):

$V=\beta \omega\left(C-C_{\mathrm{e}}\right)$

where $\beta$ is the kinetic coefficient and $\omega$ is the specific molecular volume of the crystal. The rate of advancement of etch pit step edges exhibits linear kinetics in Fig. 4a, as predicted by Eq. (3), suggesting a high kink density. In addition, the morphology of etch pits assures that the step edges of etch pits are always terminated by two kinks. In other words, etch pit step edges have a constant source of kinks.

In the case of 2D nuclei, however, a simple linear relationship cannot describe the kinetic behavior, as presented in Fig. 4c. It is highly likely that the growth of $2 \mathrm{D}$ nuclei is kink-limited, especially at low supersaturation. Zhang and Nancollas (1990) included a kink density factor in the step-edge kinetic model to give (De Yoreo and Vekilov, 2003):

$V=\beta \omega\left[C-C_{\mathrm{e}}-C_{\mathrm{e}} f\left(n_{1}\right)\right]$

where $n_{1}$ refers to the kink density on a step edge and $f\left(n_{1}\right)$ is a function of $n_{1}$ that rises linearly at low supersaturation and remains constant at high concentrations. Because of the presence of the concentration-dependent term $C_{\mathrm{e}} f\left(n_{1}\right)$, the relationship between step kinetics $\mathrm{V}$ and solute concentration $\mathrm{C}$ is non-linear, with the slope equal to $\beta \omega\left[1-\frac{1+f\left(n_{2}\right)}{C} \cdot C_{\mathrm{e}}\right]$ for the $V$ vs. $C$ curve. This concentration-dependent slope is expected to increase with increasing solute concentration and approach $\beta \omega$ at high concentration, which agrees with what is observed in Fig. 4c for the growth of 2D nuclei. As demonstrated in Fig. 4c, the slope of the growth rate versus $\left[\mathrm{Cd}^{2+}\right]_{0}$ is steeper for $\left[\mathrm{Cd}^{2+}\right]_{0}$ $\geqslant 0.070 \mathrm{mM}$ than for $0.025 \mathrm{mM} \leqslant\left[\mathrm{Cd}^{2+}\right]_{0} \leqslant 0.070 \mathrm{mM}$ and the slope for $\left[\mathrm{Cd}^{2+}\right]_{0} \geqslant 0.070 \mathrm{mM}$ approaches that of the etch pit closing (shown by the dashed line). The 2D nuclei are surrounded by smooth step edges whose advancement requires the nucleation of kink sites, particularly at low supersaturation. Enhanced supersaturation leads to an increased kink density and above a certain value the growth of $2 \mathrm{D}$ nuclei is no longer kink-limited, resulting in a kinetic behavior similar to that of the kink-rich etch pits.

\section{CONCLUSIONS}

This study reveals that the kinetics and mechanisms of heteroepitaxial growth of cadmium carbonate on the calcite $(10 \overline{1} 4)$ surface vary with the initial $\mathrm{Cd}^{2+}$ concentration. The increase in initial supersaturation promotes a transition in the growth mechanism from 3D island growth to 2D nuclei spreading, which can be explained by the difference in free energy barriers for nucleation of the two mechanisms. 3D nucleation is suggested to follow a non-classical pathway involving the formation of a lower-crystallinity precursor, which transforms to a more stable crystalline phase as growth proceeds. Differences in step kinetics are observed for monolayers and etch pit steps, which originate from differences in their kink density.

The kinetics and mechanisms of heteroepitaxial growth obtained from the present work can be used as part of a foundation for the development of predictive geochemical 
models that involve heteroepitaxy in aqueous environments. Future studies will extend this work to the kinetics of growth of carbonate phases that show greater extents of mismatch with calcite, such as manganese and cobalt carbonates.

\section{ACKNOWLEDGMENTS}

M.X. and S.K. acknowledge Dr. Shawn Chatman for his assistance with operating the AFM instrument. We would also like to thank Tom Resch for performing the ICP-OES analyses. This work was supported by the Geosciences Research Program of the U.S. Department of Energy (DOE), Office of Basic Energy Sciences. The research was performed using the Environmental Molecular Sciences Laboratory (EMSL), a national scientific user facility sponsored by the DOE's Office of Biological and Environmental Research and located at Pacific Northwest National Laboratory (PNNL). PNNL is operated for DOE by Battelle Memorial Institute under Contract \# DE-AC06-76RLO-1830. We thank Dr. Sahai and the two anonymous reviewers for their valuable comments.

\section{REFERENCES}

Arvidson R. S., Ertan I. E., Amonette J. E. and Luttge A. (2003) Variation in calcite dissolution rates: a fundamental problem? Geochim. Cosmochim. Acta 67, 1623-1634.

Astilleros J. M., Pina C. M., Fernández-Díaz L., Prieto M. and Putnis A. (2006) Nanoscale phenomena during the growth of solid solutions on calcite 10-14 surfaces. Chem. Geol. 225, 322335.

Bracco J. N., Grantham M. C. and Stack A. G. (2012) Calcite growth rates as a function of aqueous calcium-to-carbonate ratio, saturation index, and inhibitor concentration: insight into the mechanism of reaction and poisoning by strontium. Cryst. Growth Des. 12, 3540-3548.

Chada V. G. R., Hausner D. B., Strongin D. R., Rouff A. A. and Reeder R. J. (2005) Divalent Cd and Pb uptake on calcite 10-14 cleavage faces: an XPS and AFM study. J. Colloid Interface Sci. 288, 350-360.

Chernov A. A. (1984) Modern Crystallography III: Crystal Growth. Springer-Verlag, Berlin.

Chiarello R. P. and Sturchio N. C. (1994) Epitaxial growth of otavite on calcite observed in situ by synchroton X-ray scattering. Geochim. Cosmochim. Acta 58, 5368-5633.

Chiarello R. P., Sturchio N. C., Grace J. D., Geissbuhler P., Sorensen L. B., Cheng L. and Xu S. (1997) Otavite-calcite solid-solution formation at the calcite-water interface studied in situ by synchrotron X-ray scattering. Geochim. Cosmochim. Acta 61, 1467-1474.

Christoffersen J., Rostrup E. and Christoffersen M. R. (1991) Relation between interfacial surface tension of electrolyte crystals in aqueous suspension and their solubility; a simple derivation based on surface nucleation. J. Cryst. Growth 113, 599-605.

Cubillas P. and Higgins S. R. (2009) Friction characteristics of Cdrich carbonate films on calcite surfaces: implications for compositional differentiation at the nanometer scale. Geochem. Trans. 10, 7.

Cubillas P., Köhler S., Prieto M., Causserand C. and Oelkers E. (2005) How do mineral coatings affect dissolution rates? An experimental study of coupled $\mathrm{CaCO}_{3}$ dissolution- $\mathrm{CdCO}_{3}$ precipitation. Geochim. Cosmochim. Acta 69, 5459-5476.
Davis J. A., Fuller C. C. and Cook A. D. (1987) A model for trace metal sorption processes at the calcite surface. Adsorption of $\mathrm{Cd}^{2+}$ and subsequent solid solution formation. Geochim. Cosmochim. Acta 51, 1477-1490.

De Yoreo J. J. and Vekilov P. G. (2003) Principles of crystal nucleation and growth. Rev. Mineral. Geochem. 54, 57-93.

De Yoreo J. J., A. Z.-R. L., Friddle R. W., Qiu S. R., Wasylenki L. E., Chernov A. A., Gilmer G. H. and Dove P. M. (2009) Rethinking classical crystal growth models through molecular scale insights: consequences of kink-limited kinetics. Cryst. Growth Des. 9, 5135-5144.

Freeman C. L., Harding J. H. and Duffy D. M. (2008) Simulations of calcite crystallization on self-assembled monolayers. Langmuir 24, 9607-9615.

Freij S. J., Godelitsas A. and Putnis A. (2005) Crystal growth and dissolution processes at the calcite-water interface in the presence of zinc ions. J. Cryst. Growth 273, 535-545.

Gebauer D., Völkel A. and Cölfen H. (2008) Stable prenucleation calcium carbonate clusters. Science 322, 1819-1822.

Gebrehiwet T. A., Redden G. D., Fujita Y., Beig M. S. and Smith R. W. (2012) The effect of the $\mathrm{CO}_{3}^{2-}$ to $\mathrm{Ca}^{2+}$ ion activity ratio on calcite precipitation kinetics and $\mathrm{Sr}^{2+}$ partitioning. Geochem. Trans. 13, 1 .

Harstad A. O. and Stipp S. L. S. (2007) Calcite dissolution: effects of trace cations naturally present in Iceland spar calcites. Geochim. Cosmochim. Acta 71, 56-70.

Hay M. P., Workman R. K. and Manne S. (2003) Mechanisms of metal ion sorption on calcite: composition mapping by lateral force microscopy. Langmuir 19, 3727-3740.

Jordan G., Higgins S. R., Eggleston C. M., Knauss K. G. and Schmahl W. W. (2001) Dissolution kinetics of magnesite in acidic aqueous solution, a hydrothermal atomic force microscopy (HAFM) study: step orientation and kink dynamics. Geochim. Cosmochim. Acta 65, 4257-4266.

Jun Y.-S., Kendall T. A., Martin S. T., Friend C. M. and Vlassak J. J. (2005) Heteroepitaxial nucleation and oriented growth of manganese oxide islands on carbonate minerals under aqueous conditions. Environ. Sci. Technol. 39, 1239-1249.

Killian C. E., Metzler R. A., Gong Y. U. T., Olson I. C., Aizenberg J., Politi Y., Wilt F. H., Scholl A., Young A., Doran A., Kunz M., Tamura N., Coppersmith S. and Gilbert P. U. P. A. (2009) Mechanism of calcite co-orientation in the sea urchin tooth. $J$. Am. Chem. Soc. 131, 18404-18409.

Königsberger E., Hausner R. and Gamsjäger H. (1991) Solidsolute phase equilibria in aqueous solution. $\mathrm{V}$ : the system $\mathrm{CdCO}_{3}-\mathrm{CaCO}_{3}-\mathrm{CO}_{2}-\mathrm{H}_{2} \mathrm{O}$. Geochim. Cosmochim. Acta 55, 3505-3514.

Kwak J. H., Hu J. Z., Hoyt D. W., Sears J. A., Wang C., Rosso K. M. and Felmy A. R. (2010) Metal carbonation of forsterite in supercritical $\mathrm{CO}_{2}$ and $\mathrm{H}_{2} \mathrm{O}$ using solid state ${ }^{29} \mathrm{Si},{ }^{13} \mathrm{C}$ NMR spectroscopy. J. Phys. Chem. C 114, 4126-4134.

Kwak J. H., Hu J. Z., Turcu R. C. F., Rosso K. M., Ilton E. S., Wang C., Sears J. A., Engelhard M. H., Felmy A. R. and Hoyt D. W. (2011) The role of $\mathrm{H}_{2} \mathrm{O}$ in the carbonation of forsterite in supercritical $\mathrm{CO}_{2}$. Int. J. Greenhouse Gas Control 5, 1081-1092.

Larsen K., Bechgaard K. and Stipp S. L. S. (2010) The effect of the $\mathrm{Ca}^{2+}$ to $\mathrm{CO}_{3}^{2-}$ activity ratio on spiral growth at the calcite 10 14 surface. Geochim. Cosmochim. Acta 74, 2099-2109.

Lasaga A. C. and Luttge A. (2001) Variation of crystal dissolution rate based on a dissolution stepwave model. Science 291, 24002404

Lea A. S., Amonette J. E., Baer D. R., Liang Y. and Colton N. G. (2001) Microsopic effects of carbonate, manganese, and strontium ions on calcite dissolution. Geochim. Cosmochim. Acta 65, 369-379. 
Lea A. S., Hurt T. T., El-Azab A., Amonette J. E. and Baer D. R. (2003) Heteroepitaxial growth of a manganese carbonate secondary nano-phase on the (10-14) surface of calcite in solution. Surf. Sci. 524, 63-77.

Liang Y., Baer D. R., McCoy J. M., Amonette J. E. and LaFemina J. P. (1996) Dissolution kinetics at the calcite-water interface. Geochim. Cosmochim. Acta 60, 4883-4887.

Lisgarten N. D. (1954) Oriented overgrowths of alkali halides on mica. Trans. Faraday Soc. 50, 684-690.

McBride M. B. (1980) Chemisorption of $\mathrm{Cd}^{2+}$ on calcite surfaces. Soil Sci. Soc. Am. J. 44, 26-28.

Meldrum F. C. and Sear R. P. (2008) Now you see them. Science 322, 1802-1803.

Na C. and Martin S. T. (2008) Interfacial forces are modified by the growth of surface nanostructures. Environ. Sci. Technol. 42, 6883-6889.

Na C. and Martin S. T. (2009) Growth of manganese oxide nanostructures alters the layout of adhesion on a carbonate substrate. Environ. Sci. Technol. 43, 4967-4972.

Nancollas G. H. (1982) Biological Mineralization and Demineralization. Springer-Verlag, New York.

Nehrke G., Reichart G. J., Van Cappellen P., Meile C. and Bijma J. (2007) Dependence of calcite growth rate and Sr partitioning on solution stoichiometry: non-Kossel crystal growth. Geochim. Cosmochim. Acta 71, 2240-2249.

Papadopoulos P. and Rowell D. L. (1988) The reactions of cadmium with calcium carbonate surfaces. J. Soil Sci. 39, 23-36.

Paquette J. and Reeder R. J. (1995) Relationship between surface structure, growth mechanism, and trace element incorporation in calcite. Geochim. Cosmochim. Acta 59, 735-749.

Pérez-Garrido C., Fernández-Díaz L., Pina C. M. and Prieto M. (2007) In situ AFM observations of the interaction between calcite (10-14) surfaces and Cd-bearing aqueous solutions. Surf. Sci. 601, 5499-5509.

Pérez-Garrido C., Astilleros J. M., Fernández-Díaz L. and Prieto M. (2009) In situ AFM study of the interaction between calcite $10-14$ surfaces and supersaturated $\mathrm{Mn}^{2+}-\mathrm{CO}_{3}^{2-}$ aqueous solutions. J. Cryst. Growth 311, 4730-4739.

Pina C. M., Enders M. and Putnis A. (2000) The composition of solid solutions crystallising from aqueous solutions: the influence of supersaturation and growth mechanisms. Chem. Geol. 168, 195-210.

Plummer L. N., Wigley T. M. L. and Parkhurst D. L. (1978) The kinetics of calcite dissolution in $\mathrm{CO}_{2}$-water systems at $5{ }^{\circ} \mathrm{C}$ to $60{ }^{\circ} \mathrm{C}$ and 0.0 to $1.0 \mathrm{~atm} \mathrm{CO}_{2}$. Am. J. Sci. 278, 179-216.

Politi Y., Metzler R. A., Abrecht M., Gilbert B., Wilt F. H., Sagi I., Addadi L., Weiner S. and Gilbert P. U. P. A. (2008) Transformation mechanism of amorphous calcium carbonate into calcite in the sea urchin larval spicule. Proc. Natl. Acad. Sci. 105, 17362-17366.

Pouget E. M., Bomans P. H. H., Goos J. A. C., Frederik P. M., de With G. and Sommerdijk N. A. J. M. (2009) The initial stages of template-controlled $\mathrm{CaCO}_{3}$ formation revealed by cryoTEM. Science 323, 1455-1458.
Prieto M., Putnis A. and Fernández-Díaz L. (1993) Crystallization of solid-solutions from aqueous-solutions in a porous-mediumzoning in (Ba, Sr)SO4. Geol. Mag. 130, 289-299.

Rai D., Felmy A. R. and Moore D. A. (1991) Thermodynamic model for aqueous $\mathrm{Cd}^{2+}-\mathrm{CO}_{3}^{2-}$ ionic interactions in high-ionic strength carbonate solutions, and the solubility product of crystalline $\mathrm{CdCO}^{3}$. J. Solution Chem. 20, 1169-1187.

Raiteri P. and Gale J. D. (2011) Water is key to nonclassical nucleation of amorphous calcium carbonate. J. Am. Chem. Soc. 132, 17623-17634.

Rock P. A., Casey W. H., McBeath M. K. and Walling E. M. (1994) A new method for determining Gibbs energies of formation of metal-carbonate solid solutions: 1 . The $\mathrm{Ca}_{x} \mathrm{Cd}_{1-x} \mathrm{CO}_{3}(\mathrm{~s})$ system at $298 \mathrm{~K}$ and 1 bar. Geochim. Cosmochim. Acta 58, 4281-4291.

Ruiz-Agudo E., Putnis C. V., Jimenez-López C. and RodriguezNavarro C. (2009) An atomic force microscopy study of calcite dissolution in saline solutions: the role of magnesium ions. Geochim. Cosmochim. Acta 73, 3201-3217.

Schulz L. G. (1951) Growth of alkali halide crystals from the vapor phase and from solution onto substrates of mica. Acta Cryst. 4, 483-486.

Stack A. G. and Grantham M. C. (2010) Growth rate of calcite steps as a function of aqueous calcium-to-carbonate ratio: independent attachment and detachment of calcium and carbonate ions. Cryst. Growth Des. 10, 1409-1413.

Stipp S. L. S., Hochella, Jr, M. F., Parks G. A. and Leckie J. O. (1992) $\mathrm{Cd}^{2+}$ uptake by calcite, solid-state diffusion, and the formation of solid-solution: interface processes observed with near-surface sensitive techniques (XPS, LEED, and AES). Geochim. Cosmochim. Acta 56, 1941-1954.

Teng H. H., Dove P. M. and DeYoreo J. J. (1999) Reversed calcite morphologies induced by microscopic growth kinetics: insight into biomineralization. Geochim. Cosmochim. Acta 63, 25072512.

Teng H. H., Dove P. M. and De Yoreo J. J. (2000) Kinetics of calcite growth: surface processes and relationships to macroscopic rate laws. Geochim. Cosmochim. Acta 64, $2255-2266$.

Tesoriero A. J. and Pankow J. F. (1996) Solid solution partitioning of $\mathrm{Sr}^{2+}, \mathrm{Ba}^{2+}$, and $\mathrm{Cd}^{2+}$ to calcite. Geochim. Cosmochim. Acta 60, 1053-1063.

van der Merwe J. H. (1949) Misfitting monolayers and oriented overgrowth. Discuss. Faraday Soc. 5, 201-214.

Weiner S., Sagi I. and Addadi L. (2005) Choosing the crystallization path less traveled. Science 309, 1027-1028.

Zhang J.-W. and Nancollas G. H. (1990) Mechanisms of growth and dissolution of sparingly soluble salts. In Mineral-Water Interface Geochemistry (eds. M. F. Hochella and A. F. White). Mineralogical Society of America.

Associate editor: Nita Sahai 